\title{
A weak germ-line excision mutation blocks developmentally controlled amplification of the rDNA minichromosome of Tetrahymena thermophila
}

\author{
Geoffrey M. Kapler and Elizabeth H. Blackburn \\ Department of Microbiology and Immunology, The University of California, San Francisco, California 94143 USA
}

During development of the somatic macronucleus of Tetrahymena thermophila, the rDNA is excised from its germ-line chromosome, rearranged into a palindrome, and amplified to $10^{4}$ copies. We have identified a cis-acting germ-line mutation, rmm11/6, that prevents amplification of the rDNA in all but $\sim 1$ in $10^{5}$ cells when it is the only rDNA allele in the developing macronucleus. The rmm11/6 mutation resides in a conserved element required for excision, the chromosome breakage sequence (Cbs) flanking the $3^{\prime}$ end of the rDNA. Surprisingly, the rmm11/6 mutation only weakly affects excision of the rDNA from its germ-line location; at least $25 \%$ of cells heterozygous for this mutation correctly excise the affected rDNA allele. In heterozygotes, when this rDNA allele is excised, it is also poorly amplified. The rDNA amplification defect caused by this mutation is not overcome by delaying amplification with the DNA synthesis inhibitor aphidicolin, indicating that rDNA excision and amplification are not experimentally separable. Our experiments provide the first evidence that the capacity to amplify the rDNA is restricted in the developing macronucleus. We propose that the rmm11/6 mutation delays excision of the rDNA and that the developmental progression of the macronucleus past a restricted window for amplification is responsible for the severe amplification defect caused by this weak rDNA excision mutation.

[Key Words: Chromosome breakage; gene amplification; rDNA; Tetrahymena]

Received July 8, 1993; revised version accepted November 8, 1993.

Developmentally programmed DNA rearrangement and amplification play important roles in many organisms. For example, rearrangements of immunoglobulin and $\mathrm{T}$ cell receptor genes are responsible for generating antibody and $\mathrm{T}$ cell diversity (for review, see Schatz et al. 1992), gene amplification events are essential for Drosophila and Sciara development (Orr-Weaver et al. 1989; Liang et al. 1993|, and amplification of rRNA genes in developing oocytes of many organisms generates the high rRNA gene dosage needed for protein synthesis (Brown and Dawid 1968). In mammals, tumorigenesis and drug resistance often result from spontaneous DNA rearrangement and gene amplification (for review, see Stark and Wahl 1984). These two processes are often associated, as chromosome breakage and inverted duplications are observed frequently in the amplified DNA regions (for review, see Stark et al. 1989).

Much of our understanding of the relationship of unprogrammed DNA rearrangements to gene amplification is of necessity derived from the characterization of products of relatively rare spontaneous events (for review, see Stark et al. 1989|. In contrast, the developmentally programmed DNA processing and amplification steps that generate the abundant minichromosome encoding the rRNA genes (rDNA) of Tetrahymena thermophila are amenable to both molecular and genetic analyses. Thus, this developmental program, which involves chromosome breakage, rearrangement, and amplification of the rDNA, serves as a useful paradigm for understanding how these processes might be regulated.

Nowhere is developmentally controlled genomic reorganization more pronounced than in the somatic macronucleus of ciliated protozoa. The ciliate $T$. thermophila contains two nuclei, the diploid germ-line micronucleus and the polygenomic somatic macronucleus. During conjugation, the new micronucleus and macronucleus are formed by differentiation of totipotent zygotic nuclei (for review, see Karrer 1986; Yao 1989). Macronuclear 
chromosomes are formed by site-specific fragmentation of the progenitor micronuclear chromosomes (Yao et al. 1987). A conserved 15-bp motif, referred to as the chromosome breakage sequence (Cbs) (Yao et al. 1987; Yu and Blackburn 1991), is required for excision of macronuclear chromosomes from adjacent micronuclear-specific sequences (Yao et al. 1990). Sequences within and adjacent to the macronuclear-destined chromosomes are eliminated (Godiska and Yao 1990), and telomeres are added to the exposed chromosome ends (Spangler et al. 1988|. The resulting macronuclear chromosomes attain a ploidy of $45 \mathrm{C}$.

In contrast to the rest of the genome, the rDNA is further amplified during macronuclear development (Yao et al. 1974). rDNA processing and amplification have been studied at the molecular level in synchronous mating cultures. The 10.3-kb rDNA is excised from its germ-line location (King and Yao 1982; Yao et al. 1985) and rearranged into a $21-\mathrm{kb}$ palindromic minichromosome (Karrer and Gall 1976), to which telomeres are added de novo (King and Yao 1982). Palindromic rDNA is then amplified to $10^{4}$ copies (Yao et al. 1974). Monomeric linear $11-\mathrm{kb}$ rDNA is transiently detected in the new macronucleus and may be a by-product of rDNA processing or an intermediate in palindrome formation (Pan and Blackburn 1981; Challoner and Blackburn 1986). The developmentally regulated rDNA processing and amplification steps are collectively termed rDNA maturation (Fig. 1).

During subsequent vegetative divisions, the rDNA remains amplified, being replicated approximately once per cell cycle (Engberg et al. 1972). As macronuclear chromosomes, including the rDNA, segregate randomly to daughter macronuclei and the macronucleus divides unequally (Preer and Preer 1979), additional mechanism(s) must contribute to maintenance of the rDNA copy number (Larson et al. 1986). The control of replication and regulation of rDNA copy number in vegetatively growing cells are collectively termed rDNA maintenance. A single vegetative replication origin has been mapped to the rDNA $5^{\prime}$-nontranscribed spacer (NTS) (Cech and Brehm 1981). It is not known whether this origin is used to amplify the rDNA.

Previously, a genetic scheme was used to isolate four mutants affected in the vegetative maintenance of the rDNA minichromosome (Larson et al. 1986; Yaeger et al. 1989; D.D. Larson, pers. comm.). This was possible because the rDNA locus is present in a single copy per haploid micronuclear genome. These mutations, which are thought to affect vegetative rDNA replication (Larson et al. 1986), map to two copies of a phylogenetically conserved sequence that is repeated in proximity to the vegetative replication origin. The promoter-proximal copy of this element is required for in vitro rRNA transcription in the closely related Tetrahymena pyriformis (Miyahara et al. 1993), suggesting a dual function in both transcription and replication, as has been observed for both viral and cellular replication determinants in other organisms (Cheng and Kelly 1989; Mul et al. 1990; Marahrens and Stillman 1992).

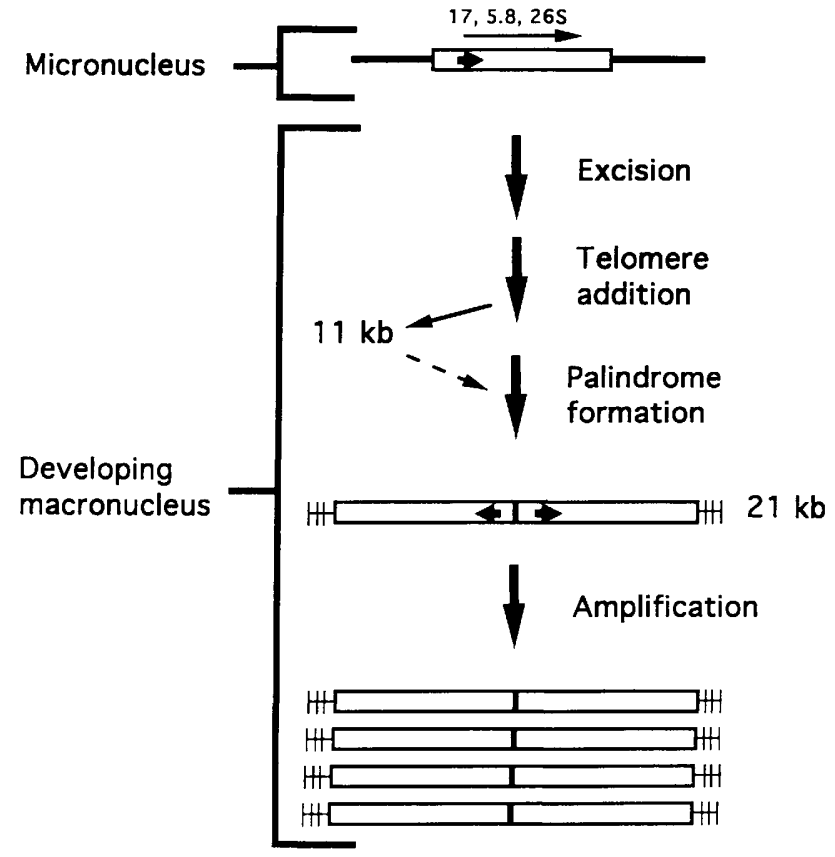

Figure 1. A proposed pathway for rDNA maturation in the developing macronucleus. The molecular forms of the rDNA in the micronucleus and developing macronucleus of mating cells are shown. The micronuclear rDNA locus (open box), encoding the $17 \mathrm{~S}, 5.8 \mathrm{~S}$, and $26 \mathrm{~S}$ rRNA genes (arrow) resides in a large chromosome (heavy flanking lines represent adjacent micronuclear DNA). In the developing macronucleus, the $10.3-\mathrm{kb}$ rDNA is excised from its germ-line location, telomeres are added, and the rDNA is rearranged into a $21-\mathrm{kb}$ head to head palindrome (short horizontal arrows denote the direction of transcription, and vertical bars on the macronuclear rDNA termini represent repeated telomeric sequences). An extrachromosomal 11-kb rDNA monomer, with telomeres on both termini, is formed in the developing macronucleus and may be an intermediate in palindrome formation. The $21-\mathrm{kb}$ palindromic rDNA is amplified to $10^{4}$ copies in the developing macronucleus.

In an effort to understand the regulation of rDNA amplification in the developing macronucleus, we isolated additional mutants using the previously developed genetic scheme (Larson et al. 1986). In this paper we describe a mutation that weakly impairs excision of the rDNA from its germ-line location. This mutation is in a sequence that becomes separated from the rDNA minichromosome upon excision. The unexpected consequence of this mutation is a strong block in the amplification of rDNA molecules that have been excised successfully. Our results reveal that the ability to amplify correctly excised rDNA is restricted during macronuclear development. We propose that the failure to amplify correctly excised rDNA results from the developmental progression of the new macronucleus past a defined period for rDNA amplification.

\section{Results}

\section{Isolation of mutants defective for rDNA maturation}

The genetic strategy devised previously for isolating mutants defective in rDNA maturation in the developing 
macronucleus and/or rDNA maintenance during vegetative growth (rmm mutants) is based on the in vivo competition between two naturally occurring rDNA alleles, $B$ and $C 3$, during vegetative growth (Pan et al. 1982; Larson et al. 1986). In a wild-type cross, $B$ and $C 3$ rDNA alleles are correctly processed and amplified in the developing macronucleus of mating cells. The $B$ rDNA, however, is rapidly lost from the macronucleus during subsequent vegetative fissions of progeny owing to a vegetative maintenance advantage for the $C 3 \mathrm{rDNA}$ minichromosome (Fig. 2A). Consequently, by $30-50$ fissions after mating, only the C3 rDNA is present in the macronucleus. In this selection protocol, progeny from this mating are initially resistant to the antibiotic paromomycin (pm) because the Pmr $1 B$ rDNA allele confers resistance to this drug (Bruns et al. 1985). Wild-type $C 3 / B$ progeny, however, become sensitive to pm during vegetative growth as a result of the loss of the $B$ rDNA from the macronucleus. Mutants that fail to produce $C 3$ rDNA in the newly developing macronucleus because of a block in one or more steps in rDNA maturation will retain the pm-resistant $\left(\mathrm{pm}^{\mathrm{r}}\right) B$ rDNA in the macronucleus rather than lose it (Fig. 2B). In previously identified mutants, maturation of the $C 3$ rDNA was normal, but subsequent $C 3 \mathrm{rDNA}$ maintenance during vegetative divisions was affected (Fig. 2C) (Larson et al. 1986; Yaeger et al. 1989; D.D. Larson, pers. comm.).

To identify mutations affecting rDNA maturation, we repeated this mutant selection protocol, mutagenizing a $C 3$ rDNA strain and mating it with a $B$ rDNA strain carrying a $\mathrm{pm}^{\mathrm{r}}$ mutation $(P m r 1)$ in its $\mathrm{rDNA}$ (for $T$. thermophila strains, see Table 1 ). $\mathrm{F}_{1}$ progeny from this mating were grown in the absence of $\mathrm{pm}$ for $\sim 70$ fissions and were then tested for resistance to pm to identify clones that retained the $B$ rDNA allele in their macronucleus. Potential $\mathrm{rmm}$ mutants $\left(\mathrm{pm}^{\mathrm{r}}\right.$ progeny at 70 fissions) were subjected to further genetic analysis to eliminate $F_{1}$ clones derived from non-germ-line phenocopies of the rmm mutant phenotype and complete deletions of the C3 rDNA locus (see Materials and methods). Of the nine new mutants, rmm5-rmm13, that reproduced the $\mathrm{rmm}$ mutant phenotype and had an intact rDNA locus, five were defective in maturation of the $C 3 \mathrm{rDNA}$ in the developing macronucleus. This paper focuses on two of them, rmm6 and $r m m 11$. More detailed descriptions of genetic methods and the genetic characterization of other $r m m$ mutants are described elswhere (G.M. Kapler, E. Orias, and E.H. Blackburn, in prep.).

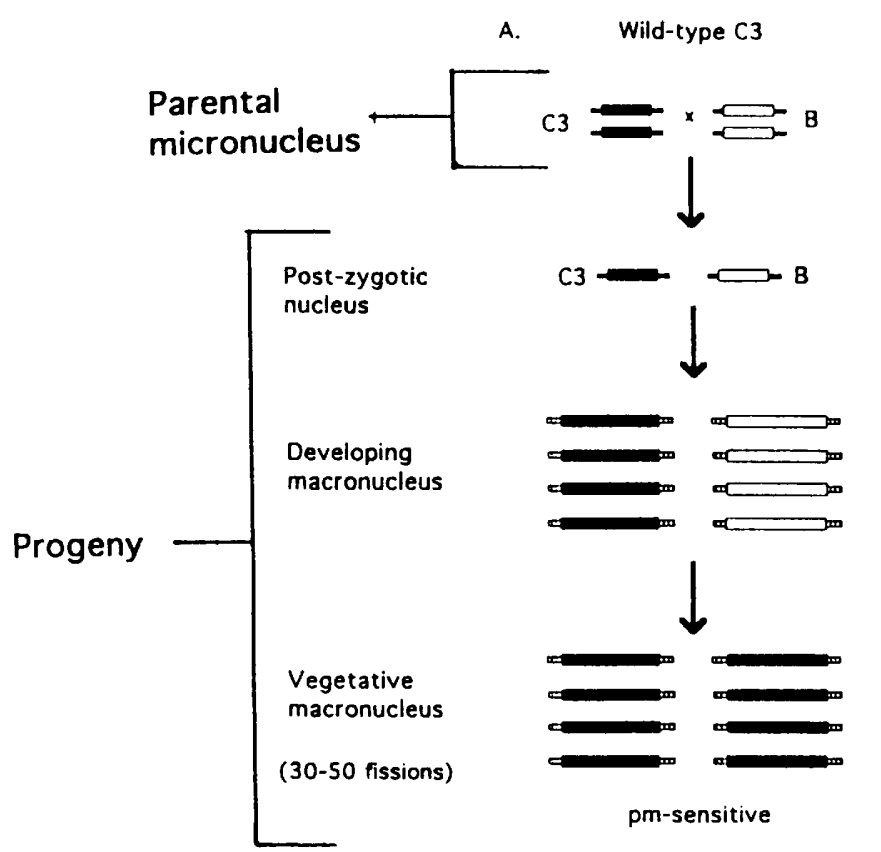

B.

C3 maturation mutant

C3

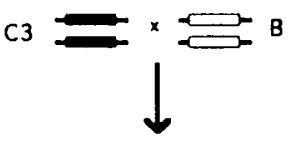

$$
\text { C3 }
$$
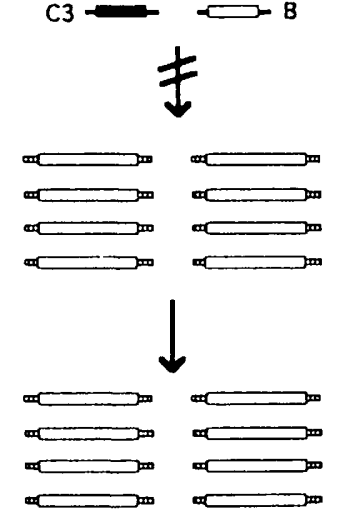

pm-resistant
C. C3 maintenance mutant

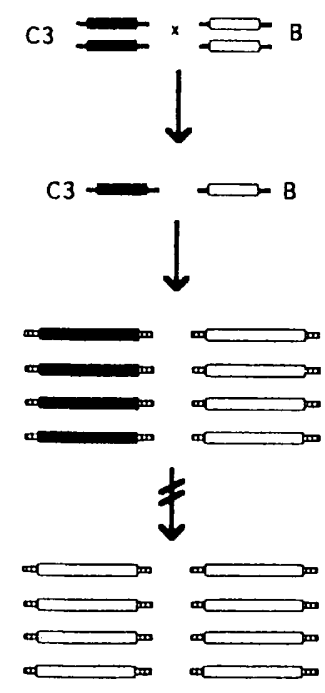

pm-resistant

Figure 2. Predicted fate of $C 3$ and $B$ rDNA in rDNA heterozygotes from matings of a $B$-Pmr1 strain with wild-type $C 3, C 3$ rDNA maturation mutant, or $C 3$ maintenance mutant strains. (Top) The parental micronuclear copy of $C 3$ (solid box) and $B$ (open box) rDNA of homozygous rDNA strains is depicted (flanking lines represent adjacent micronuclear DNA). The C3 rDNA allele confers pms, whereas the Pmr1 B rDNA allele confers $\mathrm{pm}^{\mathrm{r}}$. In all matings both $C 3$ and $B$ rDNA copies are present in the germ-line configuration in the progenitor of the new macronucleus-the postzygotic nucleus. $(A)$ In matings between a wild-type $C 3$ and $B$-Pmr1 strain, high levels of palindromic $C 3$ and $B$ rDNA are generated in the developing macronucleus of heterozygous progeny (broken line at the macronuclear rDNA termini represents telomeric DNA). By 30-50 vegetative divisions, however, the $B$ allele is lost from the macronucleus. Consequently, mature progeny are $\mathrm{pm}^{\mathrm{s}}$. $(B)$ In $C 3$ rDNA maturation mutants, only $B$ rDNA is amplified in the developing macronucleus as a result of a defect in a step in $C 3$ rDNA maturation, and progeny are stably resistant to pm. $(C)$ In $C 3$ rDNA maintenance mutants, both $C 3$ and $B$ rDNA are amplified in the developing macronucleus. The $B$ rDNA, however, is stably maintained in the macronucleus during vegetative fissions as a result of a defect in maintenance of the C3 rDNA. Again, progeny are stably resistant to $\mathrm{pm}$. 
Table 1. Genotype and phenotype of $\mathrm{T}$. thermophila strains

\begin{tabular}{|c|c|c|c|}
\hline Strain & $\begin{array}{l}\text { Micronuclear } \\
\text { genotype }\end{array}$ & $\begin{array}{l}\text { Macronuclear } \\
\text { phenotype }\end{array}$ & $\begin{array}{l}\text { Mating } \\
\text { type }\end{array}$ \\
\hline SB1934 & $\operatorname{rdn} A 4 / \mathrm{rdn} A 4, \mathrm{Mpr} / \mathrm{Mpr}$ & $6 \mathrm{mp}^{\mathrm{s}}$ & V \\
\hline SB1917 & Pmr1/Pmr1 & $\mathrm{pm}^{\mathrm{s}}$ & II \\
\hline SB1915 & ChxA2/ChxA2, Pmr1/Pmr1 & $\mathrm{cycl}^{\mathrm{s}}, \mathrm{pm}^{\mathrm{s}}$ & II \\
\hline CU374 & ChxA2/ChxA2, nulli-2L & $\mathrm{cycl}^{\mathrm{s}}$ & IV \\
\hline$A^{*}$ & functional amicronucleate & wild type & III \\
\hline SF126 & $\mathrm{rmm6} / \mathrm{rmm} 6, \mathrm{Mpr} / \mathrm{Mpr}$ & $6 \mathrm{mp}^{\mathrm{s}}$ & III \\
\hline SF122 & $\mathrm{rmm} 11 / \mathrm{rmm} 11, \mathrm{Mpr} / \mathrm{Mpr}$ & $6 \mathrm{pm}^{\mathrm{s}}$ & III \\
\hline
\end{tabular}

Locus names are as follows: (rdnA4) Wild-type C3 rDNA; $(C h \times A 2)$ cycloheximide (cycl) resistance; $(M p r)$ 6-methylpurine (6-mp) resistance; $(P m r 1) \mathrm{pm}^{\mathrm{x}} \mathrm{B}$ rDNA allele; $($ nulli-2L) partially deleted for the left arm of chromosome 2. SF126 and SF122 were derived from independent mutageneses of the wild-type $C 3$ strain SB1934 (see Materials and methods).

rmm11 and rmm6 progeny fail to amplify the C3 rDNA during macronuclear development

The rmm11 and rmm6 mutants (Table 1) were found to be defective for $C 3$ rDNA maturation, as determined by assaying for the appearance of the $C 3$ rDNA minichromosome during macronuclear development. $B$ and $C 3$ rDNA minichromosomes can be distinguished by restriction site polymorphisms in the $5^{\prime}$ and $3^{\prime}$ NTS of the rDNA (Fig. 3A). The strains used in these analyses were genetically constructed to be homozygous for the $C 3$ or $B$ rDNA alleles in their germ-line micronucleus but contain exclusively $B$ rDNA in their old parental macronucleus. Consequently, production of $C 3$ rDNA in the developing macronucleus can be assessed by Southern blotting of DNA isolated during mating. In a control cross between a wild-type $C 3$ and $B-P m r 1$ strain, C3 rDNA was amplified to a high level during macronuclear development (Fig. 3B, 15 and $24 \mathrm{hr}$ ). The C3 rDNA was monitored by use of the $2.5-\mathrm{kb} 3^{\prime}$ NTS BamHI fragment specific to this allele (Fig. 3A). In contrast, C3 rDNA was barely detected in the developing macronucleus of progeny from a mating between $r m m 11$ and the $B-P m r 1$ strain (Fig. 3C, 15 and $24 \mathrm{hr}$ ). C3 rDNA was similarly greatly underrepresented in the developing macronucleus of progeny from a mating between $\mathrm{rmm} 6$ and the $B$ rDNA strain (Fig. 3D, 15 and $24 \mathrm{hr}$ ). Southern blotting showed that the trace $C 3 \mathrm{rDNA}$ had rearranged into the normal palindromic form (data not shown; see below for $r m m 11$ clonal lines), indicating that this step was not blocked in these mutants. Hence, rmm11 and rmm6 showed a similar defect in maturation of the C3 rDNA.

\section{$\mathrm{rmm} 11$ and $\mathrm{rmm} 6$ progeny replicate their $\mathrm{C} 3$ rDNA during vegetative cell divisions}

In progeny of matings between wild-type $C 3$ and $B-P m r 1$ strains, $C 3$ and $B$ rDNA were comparably abundant at the completion of macronuclear development. By $30-40$ fissions during vegetative growth, however, the $C 3$ rDNA became the predominant macronuclear species
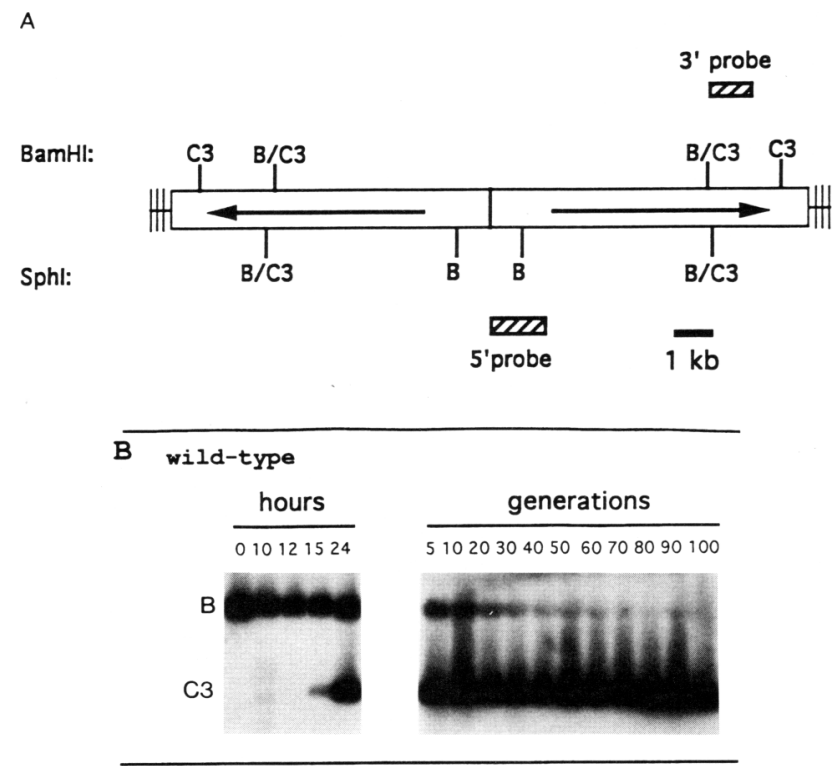

C $r \operatorname{rm} 11$
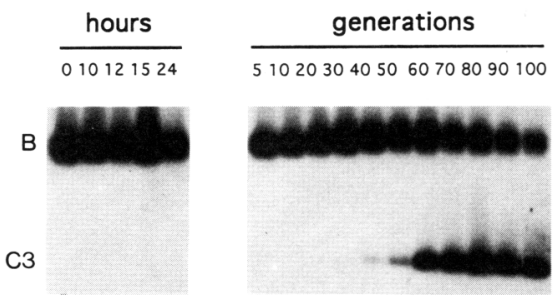

D rmm6

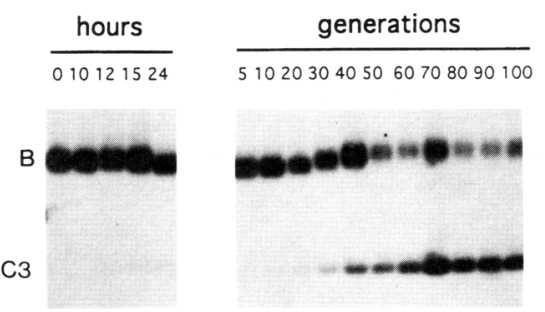

Figure 3. $C 3$ rDNA production in the developing and vegetative macronuclei of heterozygous $C 3 / B$ progeny. $(A) \mathrm{A}$ partial restriction map of the palindromic macronuclear $\mathrm{rDNA}$ is shown. The open rectangles represent the palindromic macronuclear rDNA, with arrows depicting the transcribed rRNA genes and vertical lines representing terminal telomeric sequences. Restriction site polymorphisms that were used to distinguish between $B$ and $C 3$ alleles are shown. Allele-specific BamHI fragments are detected with the $3^{\prime}$ NTS probe; allelespecific SphI fragments are distinguished with the $5^{\prime}$ NTS probe. $(B-D)$ Southern blot analyses. The B-Pmr1 strain $S B 1915$ was mated with the wild-type $C 3$ strain $S B 1934(B), r m m 11$ strain $S F 122(C)$, or rmm6 strain $S F 126(D)$. Genomic DNA was isolated from mating cultures at various times during conjugation (hours) and subsequent vegetative growth of progeny (generations|. DNA was digested with BamHI and probed with a ${ }^{32}$ P-labeled 3' NTS probe (Fig. 3A) to identify the macronuclear $B$ and $C 3$ rDNA.

(Fig. 3B). Similarly, despite their very low levels at the completion of macronuclear development, the rmm11 
and rmm6 C3 rDNA levels increased dramatically during subsequent vegetative fissions of $r m m 11 / B-P m r 1$ and $r m m 6 / B-P m r 1$ progeny (Fig. 3C,D). Both mutants routinely generated $\mathrm{pm}$-sensitive $\left(\mathrm{pm}^{\mathrm{s}}\right)$ progeny after prolonged vegetative growth of the $r m m / B-P m r 1$ heterozygotes, providing independent evidence that many progeny cells eventually lost the B rDNA during vegetative growth (rmm6, data not shown; rmm11, see below). Therefore, the processes affected in rmm11 and rmm6 must be restricted to macronuclear development, as the normal overtaking of $B$ rDNA by $C 3$ rDNA during vegetative growth is not prevented by these mutations.

\section{The rmml1 and $\mathrm{rmm} 6$ mutations reside in the rDNA $3^{\prime} \mathrm{Cbs}$}

The rmm 11 and $r m m 6$ mutations cosegregated with the C3 rDNA locus in the micronuclear genome. This was shown by generating clonal lines homozygous for the $C 3$ rDNA allele in their micronucleus and testing them for the $r m m$ mutant phenotype. For this analysis, heterozyogus $\mathrm{rmm}$ mutants were first mated with the $A^{\text {* }}$ strain, which enables such lines to retain a functional macronucleus while harboring potentially lethal mutations in the homozygous state in the micronucleus (Allen 1967) (see Materials and methods). Clonal lines homozygous for the micronuclear $C 3 \mathrm{rDNA}$ were tested for the presence of the $r m m 11$ or $r m m 6$ mutations by mating them with a $B \cdot P m r 1$ strain and periodically testing progeny for resistance to $\mathrm{pm}$. In small-scale mass matings, all homozygous micronuclear $C 3$ clones derived from $r m m 11(n=169)$ and $r m m 6(n=61)$ generated $\mathrm{pm}^{\mathrm{r}}$ progeny at 50 fissions. In contrast, a wild-type $C 3$ strain produced progeny that were exclusively $\mathrm{pm}^{\mathrm{s}}$ at this time point. Hence, the $r m m 11$ and $r m m 6$ mutations are linked to the $C 3$ rDNA locus.

Segments of the germ-line rDNA locus from rmm11 and $r m m 6$, containing all of the previously identified cis-acting elements involved in rDNA maturation and maintenance, were sequenced (Fig. 4, see expanded 5' and $3^{\prime}$ regions at top). They include the Cbs elements flanking the $5^{\prime}$ and $3^{\prime}$ end of the rDNA, which are essential for excision of the rDNA from its germ-line position (Yao et al. 1990), and the inverted repeat $M$ sequences required for palindrome formation (Yasuda and Yao 1991) (Fig. 4). All known vegetative maintenance determinants reside in the $5^{\prime}$ NTS (Fig. 4): The $B$ rDNA vegetative replication origin, which maps to domain 1 (D1) (Cech and Brehm 1981), and the evolutionarily conserved type 1 repeats, functionally identified by the $B$, $r m m 1, r m m 3$, and $r m m 4$ rDNA maintenance mutations (Larson et al. 1986; Yaeger et al. 1989; D.D. Larson, pers. comm.). These rDNA maintenance mutations have been proposed to affect vegetative rDNA replication (Larson et al. 1986) and possibly rDNA amplification as well (Orias and Bradshaw 1992).

No base changes were identified in the entire 5' NTS and its flanking micronuclear region of $r m m 11$ and rmm6. A single $A \rightarrow G$ transition, however, was identified in the 15-bp 3' Cbs element of the rmm11 mutant. The identical nucleotide substitution was also found in the 3' Cbs element of the independently isolated rmm6 mutant. This site was not mutated in all other $\mathrm{rmm}$ mutants and the parental wild-type $C 3$ strain. $r m m 11$ and $r m m 6$ were isolated in a separate mutagenesis screens performed over 1 month apart and, therefore, are independently isolated mutants. To ensure that they did not contain pre-existing mutations affecting rDNA maturation or maintenance, the starting culture for these
Figure 4. DNA sequence analysis of the rDNA locus of $\mathrm{rmm}$ mutants. The entire germ-line rDNA copy (open rectangle) and flanking micronuclear sequences (solid line) are shown at the center. The $5^{\prime}$ and $3^{\prime}$ NTSs and transcribed regions of the rDNA (arrow) are shown. The 1.9-kb $5^{\prime}$ NTS and 440 bp of flanking micronuclear DNA has been expanded. This segment contains the $\mathrm{Cbs}$ and $\mathrm{M}$ maturation determinants that are required for $5^{\prime}$ end excision and palindrome formation, respectively. The vegetative replication origin of the $B$ rDNA allele and all known rDNA maintenance determinants are also shown. These sites were identified by the 42-bp $B$ rDNA deletion and $r m m 1, r m m 4$ and $r m m 3$ mutations. Domains 1 and 2 (D1,D2) are tandem imperfect 400 -bp duplications. The vertical open rectangles

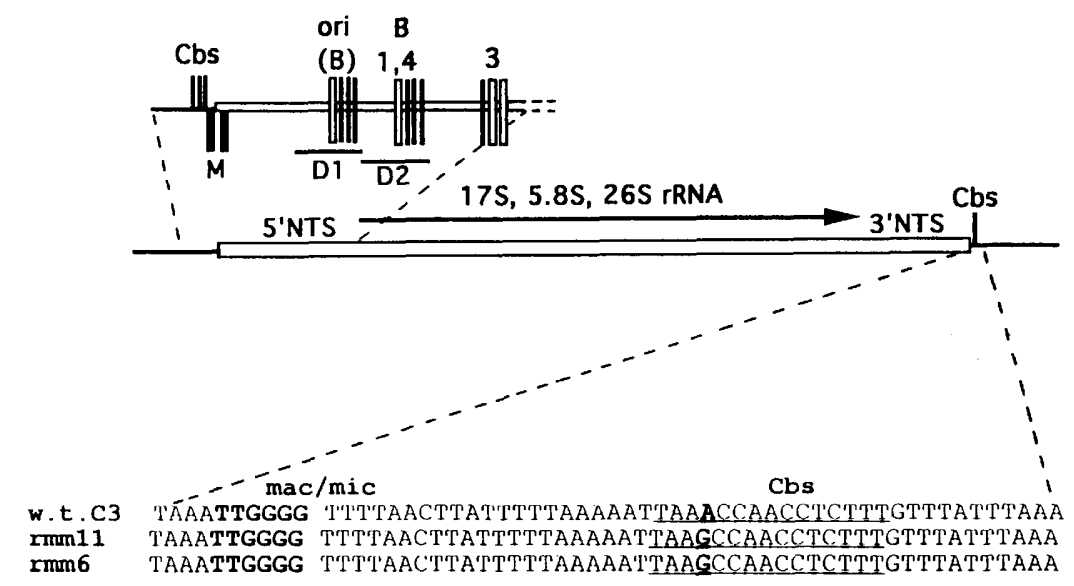
depict phylogenetically conserved type-I repeats and the vertical lines depict type-III repeats. This $5^{\prime}$ NTS region was completely sequenced for the rmm11 and rmm6 mutants, and no base changes were found. The region spanning the $3^{\prime}$ end of the rDNA gene, including the $3^{\prime}$ Cbs element, was also sequenced for $r m m 11$ (SF122) and rmm6 (SF126) strains, and a portion of the sequence is shown. The boldfaced TTGGGG sequence corresponds to terminus of the macronuclear rDNA minichromosome to which telomeres are added de novo. The 15-nucleotide Cbs element in the flanking micronuclear-specific region is underlined, and the $r m m 11$ and $r m m 6$ Cbs base changes are boldfaced. 
mutageneses consisted of random pools of 50-100 parental wild-type $C 3$ cells. The rmm 11 and rmm6 mutants were obtained with similar frequencies to other mutants with rDNA maturation and maintenance defects (G.M. Kapler, E. Orias, and E.H. Blackburn, in prep.) and with similar frequencies to Tetrahymena mutants defective in unrelated processes (Sanford and Orias 1981). These results are consistent with each $\mathrm{rmm}$ mutant harboring a single mutation responsible for its maturation or maintenance phenotypes. By all criteria tested the rmm11 and rmm6 mutants have indistinguishable phenotypes, and we conclude that these phenotypes are caused by the single nucleotide substitution in the $3^{\prime} \mathrm{Cbs}$ element.

\section{The rmm11/6 Cbs mutation weakly affects rDNA excision}

That the Cbs mutation in $r m m 11$ and $r m m 6$ did not completely prevent formation of the $C 3$ minichromosome was evident from its eventual accumulation in dividing $\mathrm{rmm} 11 / B$ and $\mathrm{rmm} 6 / B$ progeny (Fig. $3 \mathrm{C}$ ). To assess the penetrance of this Cbs mutation, clonal lines were established from progeny of a cross between rmm11 and a $B-P m r 1$ strain, and the fraction of $r m m 11 / B$ progeny that produced macronuclear $C 3$ rDNA was determined. These clonal mutant lines were assayed for $B$ and $C 3$ rDNAs early and late during vegetative growth to gain insight into the dynamics of $C 3$ rDNA maturation.

In a control mating between wild-type $C 3$ and $B-P m r 1$ strains, Southern blotting analysis determined that by 15 fissions after mating, all clonal progeny lines contained $>95 \%$ macronuclear C3 $\mathrm{rDNA}$, and at 120 fissions, only C3 rDNA was detected ( $n=24$ clones; data not shown). In contrast, at 15 fissions $r m m 11 / B-P m r 1$ clonal lines displayed a wide spectrum of $C 3 \mathrm{rDNA}$ levels, indicating that this mutation does not affect all cells equally $n=24$ clones; Fig. 5A, two representatives of each class of clones shown). At 120 fissions, $25 \%$ of these $r m m 11 / B$ Pmr1 lines had high C3 levels (Fig. 5B, the same two representatives of each class of clones shown). Clones containing high $C 3 \mathrm{rDNA}$ levels at 120 fissions (Fig. 5B, lanes 3-6) descended from lines that had either low (Fig. $5 \mathrm{~A}$, lanes 3,4 ) or comparatively high (Fig. $5 \mathrm{~A}$, lanes 5,6 ) $C 3$ levels early in vegetative growth. Sequencing analysis showed that telomeres were added at the normal position in four lines examined that excised the $C 3 \mathrm{rDNA}$ (data not shown) (King and Yao 1982; Yu and Blackburn 1991), indicating that aberrant rDNA excision did not generate the macronuclear $C 3$ rDNA in these lines. In an independent experiment in which clonal $r m m 11 / B$ $P m r 1$ lines were assayed at close intervals for sensitivity to $\mathrm{pm}$ during vegetative growth, the loss of the $\mathrm{pm}^{\mathrm{r}} B$ rDNA was significantly delayed in $r m m 11 / B$ progeny that produced macronuclear $C 3$ rDNA relative to wildtype $C 3 / B$ controls $(n=95$ clones examined; data not shown|. Collectively, these experiments revealed that the $r m m 11$ Cbs mutation has a variable penetrance for excision, affecting this process only weakly. Were the effect of this Cbs mutation confined to rDNA excision,

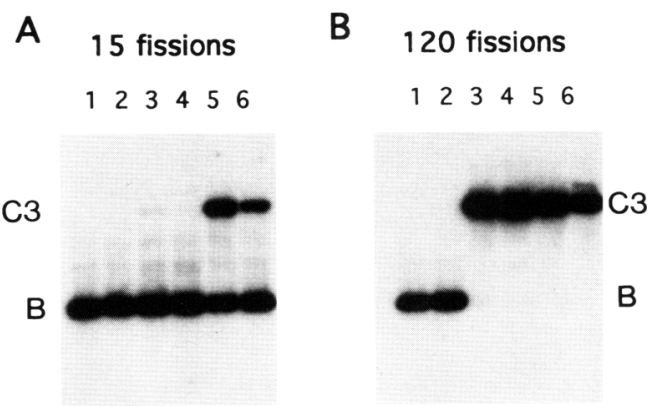

Figure 5. $C 3 \mathrm{rDNA}$ production in clonal $\mathrm{rmm} 11 / \mathrm{B}-\mathrm{Pmr} 1$ heterozygotes. Southern blot analysis of genomic DNA from six clonal $r m m 11 / B-P m r 1$ progeny derived from a mating between SF122 and SB1915 strains. Southern blotting analyses of two representative clones of the three classes of progeny lines at 15 fissions $(A)$ and 120 fissions are shown $(B \mid$. DNA was digested with SphI and hybridized to the 5' NTS probe (see Fig. 3A). The C3 rDNA that was detected is in a palindromic form (Fig. 3A). The same representative clones are shown in the corresponding lanes of $A$ and $B$.

the $C 3$ rDNA abundance in $r m m 11 \times B$ mass matings would have been at most fourfold lower than in wildtype $C 3 \times B$ controls (because $\sim 25 \%$ of $r m m 11 / B$ progeny correctly excised the $C 3 \mathrm{rDNA}$ ), instead of the $>100$ fold lower abundance observed (Fig 3B). Furthermore, C3 rDNA was initially appreciably underrepresented even in clonal progeny that successfully excised this rDNA allele, indicating that this weak excision defect had significant consequences for subsequent rDNA amplification.

Although somatic recombination has been observed in vegetative rDNA maintenance mutants (Yaeger et al. 1989), its frequency of occurrence is much too low to explain the frequent accumulation of $C 3$ rDNA in $r m m 11 / B-P m r 1$ clones during vegetative growth. Potential recombination events would have had to initiate upstream of the $C 3$ maintenance advantage determinant in the $5^{\prime}$ NTS and also retain the $C 33^{\prime}$ NTS polymorphism present in clonal lines that contained this chromosome (Fig. 5B). As there is no selective advantage for C3 rDNA sequences in the $3^{\prime}$ NTS, it is highly unlikely that such large gene conversion events could serve as the mechanism for producing the high frequency of $\mathrm{rmm} 11 / \mathrm{B}$ Pmr 1 clones containing macronuclear C3 rDNA.

Taken together, these analyses showed that the Cbs mutation in $r m m 11$ weakly affects rDNA excision frequency but not the accuracy of telomere addition or palindrome formation. In both $\mathrm{rmm} 11$ and rmm6 mutants, however, the ability to amplify successfully excised $C 3$ rDNA was significantly reduced. These two independently isolated mutants contain the same Cbs mutation, are otherwise wild-type throughout the regions known to control rDNA maturation and maintenance, and exhibit the same underamplification of $C 3$ rDNA in mass mating cultures. Therefore, we propose that this $\mathrm{Cbs}$ mutation also causes the rDNA amplification defect. 
The rmm11/6 mutation blocks C3 rDNA amplification in a macronucleus lacking competing macronuclear B $r D N A$

The consequence of the $\mathrm{rmm} 11 / 6 \mathrm{Cbs}$ mutation on $\mathrm{C3}$ rDNA amplification was even more marked in $r m m 11$ and $r m m 6$ hemizygotes than in $r m m 11 / B$ or $r m m 6 / B$ heterozygotes. This ruled out the possibility that the $C 3$ rDNA amplification defect in these $\mathrm{rmm} / B$ heterozygotes might simply have resulted from the preferential amplification of $B$ rDNA because it was excised earlier than the $C 3$ rDNA; that is, the $C 3$ amplification phenotype was not solely attributable to competition with $B$ rDNA. When $r m m 11$ was mated with a strain deleted for the rDNA locus in its germ line, $C 3$ rDNA was not amplified in the developing macronucleus (Fig. 6, right), in contrast to matings between the wild-type $C 3$ and rDNA deletion strain (Fig. 6, left). Thus, rmm11 is defective for C3 rDNA production, even in the absence of a competing macronuclear rDNA. Viable progeny were rarely obtained from this cross (frequency of $<10^{-5}$ ), and this hemizygous lethality was linked to the C3 rDNA $(n=169)$. Presumably, only in the rare viable $\mathrm{rmm} 11$ progeny clones was the $C 3$ rDNA level obtained during macronuclear development sufficiently high for survival. When $r m m 11$ was mated with the severe cis-acting $C 3 \mathrm{rDNA}$ maturation mutant $\mathrm{rmm} 10$, which like the $B$ rDNA allele contains a wild-type $3^{\prime}$ Cbs element, $C 3$ rDNA was not formed in the developing progeny macronuclei (G.M. Kapler, unpubl.); this ruled out the possibility that $C 3 \mathrm{rDNA}$ excision in $r \mathrm{~mm} 11 / B$ heterozygotes resulted from suppression of the rmm11 mutation by transvection. Furthermore, palindromic $C 3$ rDNA was detected by PCR in DNA prepared at the end of macronuclear development from hemizygous rmm11 mass mating cultures, indicating that excision and palindrome formation were not dependent on the presence of a second rDNA allele in the developing macronucleus (data not shown; for experimental details, see Materials and methods). Because excision separates the $\mathrm{rmm} 11 / 6 \mathrm{Cbs}$

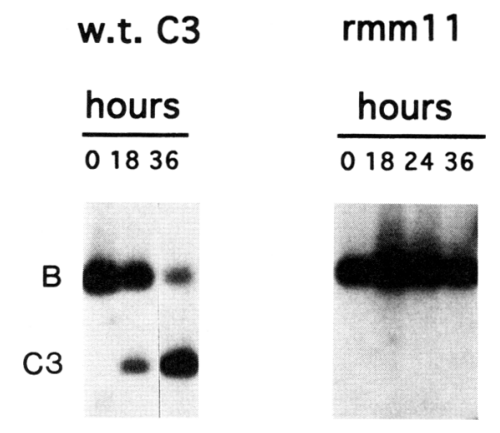

Figure 6. $C 3 \mathrm{rDNA}$ production in hemizygous wild-type $C 3$ or rmm11 macronuclei. Matings between the wild-type C3 strain SB1934 (left), or rmm11 strain SF122 (right) with strain CU374, which carries a germ-line deletion of the rDNA, were performed. Genomic DNA was isolated at various times during mating (hours), digested with BamHI, and hybridized to the $3^{\prime}$ NTS probe (Fig. 3A). mutation from the rDNA minichromosome, the effect of this mutation on subsequent amplification of the $C 3$ minichromosome must be indirect. Taken together, these results indicated that the capacity to amplify correctly excised $\mathrm{rDNA}$ is restricted in the developing macronucleus. The simplest explanation for this observation, consistent with our experimental results, is that for the rDNA to be amplified successfully, it must be excised sufficiently early during macronuclear development, and that the rmm11/6 mutation affects amplification by delaying rDNA excision.

\section{Prolonging the preamplification phase}

of macronuclear development does not suppress the rmmll mutant phenotypes

The mild and variable effect of the rmm11 mutation on rDNA excision, and its subsequent effect on $C 3 \mathrm{rDNA}$ amplification, suggested that $C 3$ rDNA is excised from the $r m m 11$ locus later than normal in macronuclear development. Consequently, in $r m m 11 / B$ heterozygotes, $B$ rDNA might have been preferentially amplified because it appeared earlier than the $C 3$ allele in the developing macronucleus. We reasoned that by delaying $B$ rDNA amplification, we might give more slowly excised $C 3$ rDNA time to "catch up" in $r m m 11 / B$ heterozygotes. Therefore, we tested whether transiently inhibiting rDNA amplification with the DNA polymerase inhibitor aphidicolin might increase the percentage of cells that amplified the $C 3 \mathrm{rDNA}$, that is, suppress the rDNA amplification phenotype in the rmm11 mutant.

In pilot experiments we determined that exposing mating cells either to $10 \mu \mathrm{g} / \mathrm{ml}$ of aphidicolin from 8 to $15 \mathrm{hr}$ after initiating mating, or to $1 \mu \mathrm{g} / \mathrm{ml}$ of aphidicolin from 14 to $24 \mathrm{hr}$, had no effect on progeny viability (data not shown). Prolonged treatments with either concentration of aphidicolin, however, were lethal. Thus, there is a significant, but restricted, tolerated window for exposure to this drug. PCR experiments showed that aphidicolin did not prevent rDNA excision (methods to be described elsewhere; data not shown). The effect of aphidicolin on wild-type $C 3 \mathrm{rDNA}$ amplification in $C 3 / B$ Pmr1 progeny was then determined (Fig. 7A). In untreated matings, $C 3$ rDNA was first detected between 12 and $14 \mathrm{hr}$ and increased significantly as macronuclear development proceeded. Exposure of wild-type matings to $10 \mu \mathrm{g} / \mathrm{ml}$ of aphidicolin from 8 to $15 \mathrm{hr}$, starting before the beginning of normal rDNA excision, arrested rDNA amplification in the developing macronucleus (Fig. 7A, cf. treated and untreated panels, C3 rDNA levels at 17 or $20 \mathrm{hr}$ ). Upon removal of the drug, rDNA amplification was detectable after a lag of a few hours, and the $C 3 \mathrm{rDNA}$ level at $33 \mathrm{hr}$ was comparable with that in untreated matings. These results revealed that the period for rDNA amplification could be shifted to a later time by this treatment of mating cells. By PCR analysis, no significant accumulation of palindromic $C 3$ rDNA was detected in cells during exposure to aphidicolin beginning at $8 \mathrm{hr}$, indicating that replication was severely impaired by this drug (data not shown). Adding 


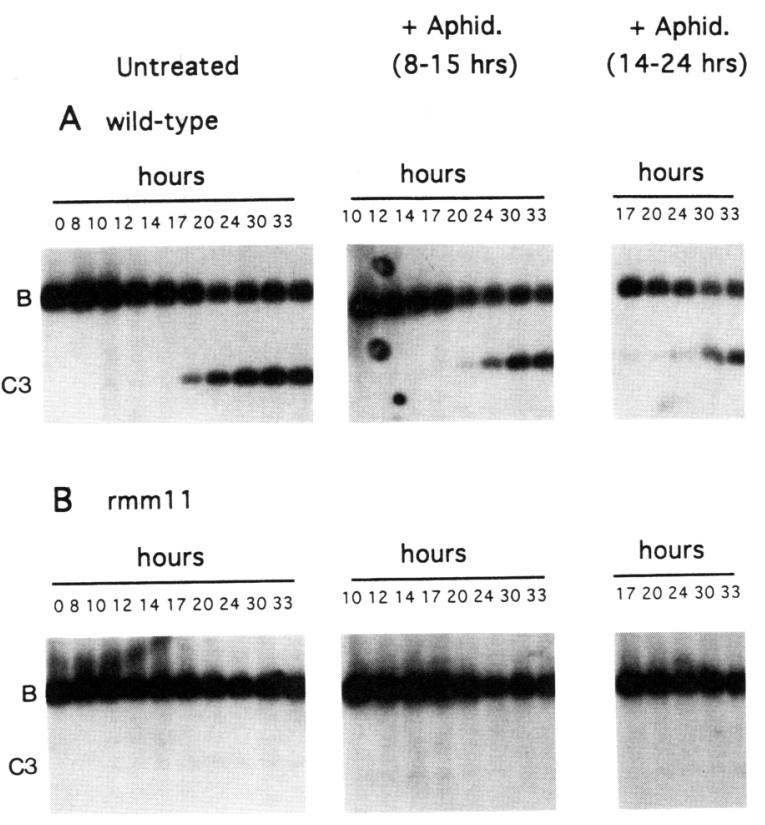

Figure 7. $C 3$ rDNA production in aphidicolin-treated mating cells. Southern blot analysis was performed on DNA isolated from matings of the wild-type C3 strain SB1934 (A) or $\mathrm{rmm} 11$ strain SF122 (B) with the B-Pmr1 strain SB1915. Mating cells were either untreated or exposed to $10 \mu \mathrm{g} / \mathrm{ml}$ of aphidicolin from 8 to $15 \mathrm{hr}$ after mixing or to $1 \mu \mathrm{g} / \mathrm{ml}$ of aphidicolin from 14 to $24 \mathrm{hr}$ after mixing, and DNA was isolated at various time points (hours). Total DNA was digested with BamHI and probed with the $3^{\prime}$ NTS probe (Fig. 3A). Southern blotting results were quantified by PhosphorImaging. The ratio of $B / C 3$ rDNA at the completion of macronuclear development was $>100$ for untreated and aphidicolin-treated $\mathrm{rmm} 11 / B$ cultures relative to wild-type $C 3 / B$ controls and was comparable in untreated and aphidicolin-treated $\mathrm{rmm} 11 / \mathrm{B}$ cells.

$1 \mu \mathrm{g} / \mathrm{ml}$ of aphidicolin from 14 to $24 \mathrm{hr}$, after wild-type rDNA excision had begun also reversibly arrested rDNA amplification; $C 3 \mathrm{rDNA}$ levels did not rise between 17 and $20 \mathrm{hr}$ (Fig. 7A). Such later treatment, however, did not block replication completely, as $C 3$ rDNA levels increased somewhat by $24 \mathrm{hr}$ (Fig. 7A). Again, the C3 rDNA was subsequently amplified to a high level upon removal of the drug. Taken together, these results suggest that factors required for amplification of the rDNA must be sufficiently stable or abundant to function after removal of aphidicolin in these temporarily arrested cells.

If aphidicolin treatment increased the percentage of rmm11/B progeny that excised the $C 3 \mathrm{rDNA}$, or temporally separated the periods for $\mathrm{rDNA}$ excision and amplification in the developing macronucleus, we would expect to observe suppression of the rDNA excision and amplification phenotypes. Neither of these phenotypes, however, was suppressed. In untreated matings between rmm11 and a $B-P m r 1$ strain, low levels of $C 3$ rDNA were detected during macronuclear development (Fig. 7B). Cells that were exposed to aphidicolin from 8 to $15 \mathrm{hr}$ or 14 to $24 \mathrm{hr}$ after mixing similarly showed low C3 rDNA levels after removal of the drug (Fig. 7B). Thus, transiently arresting rDNA amplification did not suppress the $r m m 11$ rDNA amplification defect. Aphidicolin treatment also did not increase the percentage of $r m m 11 / B$ progeny that excised the $C 3 \mathrm{rDNA}$, as indicated by the percentage of progeny that became sensitive to $\mathrm{pm}$ after prolonged vegetative growth $(n>100$ rmm11/B-Pmr1 progeny/treatment; data not shown). From these results we conclude that rDNA excision and amplification are not experimentally separable. We propose that the rmm11/6 mutation causes excision of the C3 rDNA to occur late in macronuclear development and that the periods for rDNA excision and amplification overlap extensively, so that delaying amplification does not rescue the $r m m 11 / 6$ amplification defect.

\section{Discussion}

The effect of the rmm 11/6 Cbs mutation on $r D N A$ excision

We have isolated a new class of mutants defective in the developmentally regulated maturation of the rDNA minichromosome. The cis-acting $\mathrm{rmm} 11 / 6$ mutant has a single nucleotide substitution in the Cbs element immediately flanking the $3^{\prime}$ end of the rDNA. Previous work, using DNA transformation to assay for rDNA excision, revealed that the Cbs element is necessary for chromosome breakage and dictates the position of subsequent telomere addition (Yao et al. 1990). The 15-bp Cbs element is thought to play a role in excision of nonrDNA macronuclear chromosomes as well, because a copy of this sequence is found in the progenitor micronuclear chromosomes in proximity to the ends of all analyzed macronuclear-destined chromosomal regions (Yao et al. 1987; Yu and Blackburn 1991). The rmm11/6 Cbs mutation causes only a weak defect in rDNA excision, as at least $25 \%$ of progeny heterozygous for this mutation correctly excise the affected rDNA allele. Telomeres are added to the normal position in these lines, indicating that aberrant processing of the $C 3$ chromosome did not generate these macronuclear rDNA minichromosomes. Previous transformation studies revealed that the $3^{\prime}$ terminal $500 \mathrm{bp}$ of the rDNA is nonessential, implying that aberrant sites for telomere addition could have been tolerated (Yao et al. 1990). Additional experiments on the rmm11 mutant ruled out the possibility that somatic recombination or transvection between micronuclear rDNA loci could account for the high frequency appearance of the macronuclear $C 3$ minichromosome in heterozygous rmm11 progeny cells. Collectively, these findings indicate that this mutated $\mathrm{Cbs}$ element is still functional, causing a weak rDNA excision defect that decreases the probability of excising the affected rDNA allele. Because the rmm11/6 Cbs mutation is in the germ line and is recessive-lethal, it may be possible to identify factors that control macronuclear chromosome breakage by selecting for extragenic suppressors of this rDNA excision mutation. 
The effect of the rmml1/6 Cbs mutation on rDNA amplification

The analysis of clonal $\mathrm{rmm} 11 / \mathrm{B}$ lines revealed that although the $r m m 11 / 6$ mutation only weakly affects excision of the $C 3 \mathrm{rDNA}$, subsequent amplification is dramatically affected, even in progeny that do successfully excise the $C 3$ rDNA. In mass cultures of $r m m 11 / B$ progeny, C3 rDNA was grossly underrepresented relative to the percentage of progeny that formed the macronuclear C3 minichromosome. We reasoned that if competition with the $B$ rDNA was the sole basis for the rDNA amplification phenotype caused by the rmm11/6 mutation, C3 rDNA would be amplified to a high level in hemizygous progeny. In fact, the exact opposite was observed: rmm11 hemizygotes lacking a competing macronuclear $B$ rDNA failed to amplify the $C 3$ rDNA. Hemizygous viable progeny were formed at a very low frequency $\left(<10^{-5}\right)$. Presumably, only in these rare progeny was the C3 rDNA amplified sufficiently for viability. These results provide the first evidence that the ability to amplify correctly excised rDNA is restricted in the developing macronucleus. Thus, rDNA amplification is not solely controlled by a mechanism that counts the number of rDNA minichromosomes. As the $r m m 11 / 6 \mathrm{Cbs}$ element is still functional, but decreases the probability of $C 3$ rDNA excision, we propose that the $r m m 11 / 6$ mutation delays $C 3$ rDNA excision, such that successfully excised molecules appear too late to be properly amplified.

Previous DNA transformation studies determined that unrearranged micronuclear rDNA constructs transform optimally when introduced into mating cells at early times (Yao and Yao 1989). One possibility is that this results from restricted developmental windows for excision and/or amplification; however, it cannot be excluded that transformation at early times is more effective, simply because incoming rDNA has to compete with endogenous rDNA. Current DNA transformation methods cannot distinguish between these and other possibilities, in part because the low frequency of transformation allows only for the characterization of products of relatively rare successful tranformation events, a situation similar to the analyses of spontaneous gene amplifications in higher eukaryotes (for review, see Stark et al. 1989).

Because the rmm11/6 excision mutation is in the germ line, its effect on downstream steps in rDNA maturation could be studied. The effect of the $r m m 11 / 6 \mathrm{mu}$ tation on the amplification process was unexpected, because the mutation is physically separated from the rDNA minichromosome upon excision. Therefore, after excision, the Cbs mutation cannot affect rDNA amplification in cis. Because we have shown that rDNA amplification is not only dependent on whether or not the rDNA is excised, we propose that this partial loss-offunction mutation affects the timing of excision in progeny that excise the affected $C 3 \mathrm{rDNA}$ allele. This model predicts that the periods for rDNA excision and amplification must overlap. If excision and amplification were restricted to separate stages of macronuclear develop- ment, the rmm11/6 rDNA excision mutation would not have affected subsequent $C 3$ rDNA amplification in progeny that successfully excised the $C 3$ rDNA. The concept of overlapping windows for excision and amplification was supported by the results of transiently arresting rDNA amplification with aphidicolin. In control experiments, aphidicolin treatment did not block wildtype rDNA excision but delayed its subsequent amplification. The amplification defect of rmm11, however, was not overcome by aphidicolin treatment, indicating that rDNA excision and amplification were not experimentally separable.

The regulation of rDNA amplification is not well understood. Previous work showed stochastic variation in the ratio of $B$ and $C 3 \mathrm{rDNAs}$ in individual mating exconjugants, indicating that the relative degree of amplification of the two rDNA alleles is not rigidly controlled (Orias and Bradshaw 1992). We have provided the first evidence that the ability to amplify the rDNA is restricted in the developing macronucleus. Amplification of the rDNA during conjugation and its maintenance during vegetative growth are likely to be controlled by factors involved in replication initiation and factors that determine the absolute level of rDNA in the macronucleus (Larson et al. 1986). The restriction on rDNA amplification revealed by our $r m m 11 / 6$ studies may result from alterations in the abundance of specific activators and/or repressors of rDNA amplification during the progression of macronuclear development. Conversely, a more general mechanism might delimit the period for rDNA amplification. The onset of transcription and dynamic changes in histone composition occur during new macronuclear development (Allis and Wiggins 1984; Wenkert and Allis 1984; Lin et al. 1989; White et al. 1989). Such gross nuclear changes could have a profound effect on the accessibility of cis-acting amplification determinants to cognate trans-acting factors. It is likely that the multitude of processes involved in macronuclear development are coordinately regulated through a dynamic developmental program. The dependence of developmentally regulated rDNA amplification on the timing of chromosome breakage is the first example of the consequences of perturbing the coordinate regulation of these processes.

As tumors and drug-resistant mammalian cells frequently contain amplified DNA regions that have been excised and rearranged (for review, see Stark et al. 1989), understanding the relationship of chromosome breakage and rearrangement to the process of gene amplification is of considerable interest. The developmental coordination of these events in the rDNA minichromosome may provide insight into the mechanisms that regulate these processes in higher eukaryotes.

\section{Materials and methods \\ Cell culture and Tetrahymena strains}

Unless otherwise stated, all cultures were grown in $2 \%$ proteose-peptone supplemented with $10 \mu \mathrm{m}$ of $\mathrm{FeCl}_{3}, 250 \mu \mathrm{g} / \mathrm{ml}$ of 
penicillin, $250 \mu \mathrm{g} / \mathrm{ml}$ of streptomycin, and $25 \mu \mathrm{g} / \mathrm{ml}$ of amphotericin B. Standard genetic procedures have been described previously (Orias and Bruns 1975; Orias and Hamilton 1979). Tetrahymena strains relevant to this paper are listed in Table 1. Mutagenesis of the wild-type C3 strain SB1934 with nitrosoguanidine was performed as described previously (Roberts and Orias 1973).

\section{Isolation of rmm mutants}

The $C 3$ rDNA strain $S B 1934$ was mutagenized and mated with the B-Pmr1 strain SB1917, refed at $24 \mathrm{hr}$ after mixing cultures to initiate mating by dilution to $1 \%$ proteose-peptone, and distributed to 96-well microtiter dishes at 200 cells $/$ well $\left(2 \times 10^{5}\right.$ cells $/$ mutagenesis experiment). Cross-fertilized progeny were selected sequentially with $\mathrm{pm}(200 \mu \mathrm{g} / \mathrm{ml})$ and 6-methylpurine $(15 \mu \mathrm{g} / \mathrm{ml})$ and then replica transferred in nonselective media for 10 passages $(\sim 70$ fissions $) . F_{1}$ progeny that retained the $B$ rDNA allele in the macronucleus were identified by selection for resistance to $\mathrm{pm}$ at $\sim 70$ fissions as described previously (Larson et al. 1986). From three independent mutagenesis experiments, $2300 \mathrm{pm}^{\mathrm{r}} \mathrm{F}_{1}$ progeny were identified.

Genetic analysis of potential $\mathrm{rmm}$ mutants was performed essentially as described previously (Larson et al. 1986). $\mathrm{Pm}^{\mathrm{r}} \mathrm{F}_{1}$ progeny were crossed with the B-Pmr1 strain SB1915. $\mathrm{F}_{2}$ progeny were selected with cycloheximide, and eight progeny cells were isolated separately into pm, at 30 fissions. $F_{2}$ crosses with progeny that were all $\mathrm{pm}^{\mathrm{r}}$ were analyzed further. Phenocopies of the $\mathrm{rmm}$ mutant phenotype would have a C3/B-Pmr1, $\mathrm{rmm}^{+}$/ $\mathrm{rmm}^{+}$genotype in $\mathrm{F}_{1}$ progeny. These $\mathrm{F}_{1}$ progeny were identified as producing stable $\mathrm{pm}^{\mathrm{r}}$ in $\sim 50 \%$ of progeny from this $\mathrm{F}_{2}$ cross and were eliminated from further consideration.

Approximately $90 \%$ of the analyzed clones were phenocopies (frequency of this class, $10^{-3}$ of total $F_{1}$ progeny). They did not produce $\mathrm{pm}^{\mathrm{r}}$ progeny at $\sim 70$ fissions upon retesting, and therefore did not carry a germ-line rmm mutation.

$F_{1}$ progeny that produced exclusively $\mathrm{pm}^{\mathrm{r}}$ clones in the $\mathrm{F}_{2}$ cross were mated with the $A^{*}$ strain to generate progeny that were whole genome micronuclear homozygotes by round 1 genomic exclusion (Allen 1967). The new homozygous micronucleus is derived from a single haploid meiotic product of the $F_{1}$ clone, and these round 1 progeny retain the old macronucleus of either the $\mathrm{F}_{1}$ or $A^{\star}$ strains. Consequently, strains carrying dominant or recessive lethal mutations in their germ lines can be obtained. Previously described test crosses were used to identify lines that were deleted for the entire rDNA or were homozygous for the C3 rDNA in their micronucleus. (Gross chromosomal deletions likely to include the rDNA locus occurred at a frequency of $10^{-4}$ of $F_{1}$ progeny.) Whole genome $C 3$ homozygotes were retested for the $\mathrm{rmm}$ mutant phenotype by mating them with the B-Pmr1 strain SB1915 and assaying for resistance to pm during vegetative growth. Nine new $\mathrm{rmm}$ mutants, which reproduced the $\mathrm{pm}^{\mathrm{r}}$ phenotype during vegetative fissions in $\mathrm{B} / \mathrm{C} 3$ heterozygotes, were identified (frequency of this class, $10^{-5}$ of $F_{1}$ progeny).

\section{Genetic linkage analysis}

Micronuclear homozygotes were generated by round 1 genomic exclusion of $\mathrm{rmm} 11$ and $\mathrm{rmm} 6 \mathrm{~F}_{1}$ progeny $\left(\mathrm{rmm} / \mathrm{rmm}^{+}, C 3 / B\right.$ Pmr1) with the functional amicronucleate $A^{\star}$ strain. $A^{\star}$ cross progeny are homozygous at all loci in their micronuclear genome but retain their parental macronucleus (Allen 1967). Consequently, lethal mutations can be carried in a homozygous state in the micronucleus of these strains. Whole genome homozygotes that carried the $\mathrm{Pmr}^{+} \mathrm{C} 3 \mathrm{rDNA}$ allele in their mi- cronucleus were identified and then crossed with the $B-P m r 1$ strain SB1915 to assess whether the rmm mutation cosegrgated with the $C 3$ rDNA allele. Progeny from this cross were periodically tested for resistance to pm between 20 and 120 fissions. Meiotic recombination between the $C 3$ rDNA and the $\mathrm{rmm}$ mutation would generate lines that reproducibly produce $\mathrm{pm}^{\mathrm{s}}$ progeny in this test cross by $30-50$ fissions.

\section{DNA isolation and Southern blot analysis}

Total genomic DNA was isolated as described previously (Larson et al. 1986). Agarose gel electrophoresis and transfer to nylon membranes (Nytran, Schleicher \& Schuell) were performed using standard procedures. Cloned rDNA fragment probes were radiolabeled by random priming with $\left[{ }^{32} \mathrm{P}\right] \mathrm{dATP}$.

\section{Developmental time course experiments}

For the analysis of DNAs during conjugation and vegetative fissions, whole genome homozygotes of wild-type C3 (SB1934), rmm11 (SF122) and rmm6 (SF126) strains were mated with the $B$-Pmr1 strain SB1915, and DNA was isolated from mating cultures at various times during mating and vegetative fissions of progeny. Mated cells were refed at $24 \mathrm{hr}$ after mixing; crossfertilized exconjugants were selected sequentially with cycloheximide and 6-methylpurine, and subsequently grown in nonselective media during vegetative fissions. In all matings, parental strains were heterokaryons containing exclusively $B$ rDNA in their macronucleus. For the analysis of clonal $\mathrm{rmm} 11 /$ $B-P m r 1$ heterozygotes, clonal lines were established by limiting dilution and replica transferred during vegetative fissions.

For experiments using the drug aphidicolin, mated cells were either treated with $10 \mu \mathrm{g} / \mathrm{ml}$ of aphidicolin from 8 to $15 \mathrm{hr}$ after mixing or $1 \mu \mathrm{g} / \mathrm{ml}$ of aphidicolin from 14 to $24 \mathrm{hr}$ after mixing, or untreated. Aphidicolin was removed by washing cells twice in drug-free mating media. All matings were refed at $33 \mathrm{hr}$ after mixing, and progeny were selected as described above. These drug exposure conditions had essentially no effect on the viability of progeny. In contrast, exposure to $10 \mu \mathrm{g} / \mathrm{ml}$ aphidicolin from 8 to $24 \mathrm{hr}$ after mixing prevented the formation of viable progeny (progeny viability frequency $<10^{-4}$ ).

\section{PCR amplification and DNA sequencing}

of the micronuclear rDNA gene and macronuclear

rDNA telomere addition sites

To sequence the micronuclear rDNA locus of rmm11, rmm6, and wild-type $C 3$ strains, PCR amplification of the germ line was performed using primers located in the $5^{\prime}$ NTS or $3^{\prime}$ NTS regions of the rDNA in conjunction with primers located in the flanking micronuclear regions. PCR amplification of the $1.9-\mathrm{kb}$ $5^{\prime}$ NTS and $400 \mathrm{bp}$ of flanking micronuclear sequences was performed for $\mathrm{rmm} 11, \mathrm{rmm} 6$, and wild-type $C 3$ strains with primers 1 and 2 , using the following thermocycler program: $94^{\circ} \mathrm{C}$ for $1 \mathrm{~min}, 50^{\circ} \mathrm{C}$ for $1 \mathrm{~min}, 72^{\circ} \mathrm{C}$ for $3 \mathrm{~min}$, for 40 cycles, followed by $10 \mathrm{~min}$ at $72^{\circ} \mathrm{C}$. One microliter of PerfectMatch (Stratagene) was added to each $100-\mu 1$ reaction to increase the primer specificity. The resulting $2.3-\mathrm{kb}$ PCR product was cloned into the SmaI site of pUC119. PCR amplification of a 170-bp segment containing the terminus of the $3^{\prime}$ NTS and flanking micronuclear sequences was performed for $r \mathrm{~mm} 11$, rmm6, and wild-type $C 3$ strains with primers 3 and 4 as described above, and similarly cloned into pUC119. The 170-bp product was cloned as described above. Both DNA strands were sequenced by the dideoxy method using rDNA-specific primers from multiple PCR reactions to ensure that any base changes 
were not PCR artifacts. The telomere addition site of $\mathrm{rmm} 11 /$ $B-P m r 1$ clones that contained exclusively $C 3$ rDNA in their macronucleus was determined by sequencing PCR products generated with primer 3 and primer 5 using the above thermocycler program. Primer 1, 5'-CAGTTATAAAAATAGTGTTTCATG; primer 2, 5'-TCTTACTGAAGCTCAAATCGAGCTG; primer 3, 5'-AATAACCAAAAATCAAAG; primer 4, 5'-CAATAATGTATTAAAAATATGCTACTTATGCATTATC; primer 5, 5'-CCCCAACCCCAACCCCAACCCCA.

\section{Acknowledgments}

We are indebted to Dr. Eduardo Orias for his expert guidance in genetic methods in Tetrahymena and laboratory facilities for the initial mutagenesis experiments, as well as numerous scientific discussions. We also thank R. Gallagher, K. Kirk, A. Bhattacharyya, P. Cohen, and D. Shippen for helpful discussions and critical reading of the manuscript. This work was supported by National Institutes of Health grant GM-32565. G.M.K. was supported by a Damon Runyon-Walter Winchell Cancer Research Fund postdoctoral fellowship award. Laboratory facilities were provided in part by the Lucille P. Markey Charitable Trust.

The publication costs of this article were defrayed in part by payment of page charges. This article must therefore be hereby marked "advertisement" in accordance with 18 USC section 1734 solely to indicate this fact.

\section{References}

Allen, S.L. 1967. Cytogenetids of genomic exclusion in Tetrahymena. Genetics 55: 797-822.

Allis, C.D. and J.C. Wiggins. 1984. Histone rearrangements accompany nuclear differentiation and dedifferentiation in Tetrahymena. Dev. Biol. 101: 282-294.

Brown, D.D. and I.B. Dawid. 1968. Specific gene amplification in oocytes. Science 160: 272-280.

Bruns, P.J., A.L. Katzen, L. Martin, and E.H. Blackburn. 1985. A drug resistance mutation maps in the ribosomal DNA of Tetrahymena. Proc. Natl. Acad. Sci. 82: 2844-2846.

Cech, T.R. and S.L. Brehm. 1981. Replication of the extrachromosomal ribosomal RNA genes of Tetrahymena thermophila. Nucleic Acids Res. 9: 3531-3543.

Challoner, P.B. and E.H. Blackburn. 1986. Conservation of sequences adjacent to the telomeric $\mathrm{C}_{4} \mathrm{~A}_{2}$ repeats of ciliate macronuclear ribosomal RNA gene molecules. Nucleic Acids Res. 14: 6299-6311.

Cheng, L. and T.J. Kelly. 1989. Transcriptional activation nuclear factor I stimulates the replication of SV40 minichromosomes in vivo and in vitro. Cell 59: 541-551.

Engberg, J., D. Mowat, and R.E. Pearlman. 1972. Preferential replication of the ribosomal RNA gene during nutritional shift-up in Tetrahymena pyriformis. Biochim. Biophys. Acta 272: $312-320$.

Godiska, R. and M.-C. Yao. 1990. A programmed site-specific DNA rearrangement in Tetrahymena thermophila requires flanking polypurine tracts. Cell 61: 1237-1246.

Karrer, K.M. 1986. The nuclear DNA of holotrichs. In The molecular biology of ciliated protozoa (ed. J.G. Gall), pp. 85110. Academic Press, Orlando, FL.

Karrer, K.M. and J.G. Gall. 1976. The macronuclear ribosomal DNA of Tetrahymena pyriformis is a palindrome. $J$. Mol. Biol. 104: 421-453.

King, B.O. and M.-C. Yao. 1982. Tandemly repeated hexanucleotide at Tetrahymena rDNA free end is generated from a single copy during development. Cell 31: 177-182.
Larson, D.D., E.H. Blackburn, P.C. Yaeger, and E. Orias. 1986. Control of rDNA replication in Tetrahymena involves a cisacting upstream repeat of a promoter element. Cell 47: 229240.

Liang, C., J.D. Spitzer, H.S. Smith, and S.A. Gerbi. 1993. Replication initiates at a confined region during DNA amplification in Sciara DNA puff II/9A. Genes Dev. 7: 1072-1084.

Lin, R., J.W. Leone, R.G. Cook, and C.D. Allis. 1989. Antibodies specific to acetylated histones document the existence of deposition- and transcription-related histone acetylation in Tetrahymena. J. Cell Biol. 108: 1577-1588.

Marahrens, Y. and B. Stillman. 1992. A yeast chromosomal origin of DNA replication defined by multiple functional elements. Science 255: 817-823.

Miyahara, K., N. Hashimoto, T. Higashinakagawa, and R.E. Pearlman. 1993. Common sequence elements are important for transcription and replication of the extrachromosomal rRNA-coding genes of Tetrahymena. Gene 127: 209-213.

Mul, Y.M., C.P. Verrijzer, and P.C. van der Vliet. 1990. Transcription factors NFI and NFIII/oct-l function independently, employing different mechanisms to enhance adenovirus DNA replication. J. Virol. 64: 5510-5518.

Orias, E. and A.D. Bradshaw. 1992. Stochastic developmental variation in the ratio of allelic rDNAs among newly differentiated, heterozygous macronuclei of Tetrahymena thermophila. Dev. Biol. 13: 87-93.

Orias, E. and P.J. Bruns. 1975. Induction and isolation of mutants in Tetrahymena. In Methods in cell biology (ed. D.M. Prescott), pp. 247-282. Academic Press, New York.

Orias, E. and E.P. Hamilton. 1979. Cytogamy: An inducible alternate pathway of conjugation in Tetrahymena thermophila. Genetics 91: 657-671.

Orr-Weaver, T.L., C.G. Johnston, and A.C. Spradling. 1989. The role of ACE3 in Drosophila chorion gene amplification. EMBO I. 8: 4153-4162.

Pan, W.-C. and E.H. Blackburn. 1981. Single extrachromosomal ribosomal RNA gene copies are synthesized during amplification of the rDNA in Tetrahymena. Cell 23: 459-466.

Pan, W.-C., E. Orias, M. Flacks, and E.H. Blackburn. 1982. Allele-specific selective amplification of a ribosomal RNA gene in Tetrahymena thermophila. Cell 28: 595-604.

Preer, J.R. and L.B. Preer. 1979. The size of macronuclear DNA and its relationship to models for maintaining genic balance. J. Protozool. 26: 14-18.

Roberts, C.T. and E. Orias. 1973. Cytoplasmic inheritance of chloramphenicol resistance in Tetrahymena. Genetics 73: 259-272.

Sanford, Y.M. and E. Orias. 1981. Phenylketonuric Tetrahymena: Phenylalanine hydroxylase mutants and tyrosine auxotrophs. Proc. Natl. Acad. Sci. 78: 7614-7618.

Schatz, D.G., M.A. Oettinger, and M.S. Schlissel. 1992. V(D)| recombination: Molecular biology and regulation. Annu. Rev. Immunol. 10: 359-383.

Spangler, E.A., T. Ryan, and E.H. Blackburn. 1988. Developmentally regulated telomere addition in Tetrahymena thermophila. Nucleic Acids Res. 16: 5569-5585.

Stark, G.R. and G.M. Wahl. 1984. Gene amplifications. Annu. Rev. Biochem. 53: 447-491.

Stark, G.R., M. DeBatisse, E. Giulotto, and G.M. Wahl. 1989. Recent progress in understanding mechanisms of mammalian DNA amplification. Cell 57: 901-908.

Wenkert, D. and C.D. Allis. 1984. Timing of the appearance of macronuclear-specific histone variant hvl and gene expression in developing new macronuclei of Tetrahymena thermophila. J. Cell Biol. 98: 2107-2117.

White, E., C.D. Allis, D.S. Goldfarb, A. Srivastva, J.W. Weir, and 
M.A. Gorovsky. 1989. Nucleus-specific and temporally restricted localization of proteins in Tetrahymena macronuclei and micronuclei. I. Cell Biol. 109: 1983-1992.

Yaeger, P.C., E. Orias, W.-L. Shaiu, D.D. Larson, and E.H. Blackburn. 1989. The replication advantage of a free linear rDNA gene is restored by somatic recombination in Tetrahymena thermophila. Mol. Cell Biol. 9: 452-460.

Yao, M.-C. 1989. Site-specific chromosome breakage and DNA deletion in ciliates. In Mobile DNA (ed. D.E. Berg and M.M. Howe), pp. 715-734. American Society for Micobiology, Washington, D.C.

Yao, M.-C. and C.-H. Yao. 1989. Accurate processing and amplification of cloned germ line copies of ribosomal DNA injected into developing nuclei of Tetrahymena thermophila. Mol. Cell Biol. 9: 1092-1099.

Yao, M.-C., A.R. Kimmel, and M.A. Gorovsky. 1974. A small number of cistrons for ribosomal RNA in the germline nucleus of a eukaryote, Tetrahymena pyriformis. Proc. Natl. Acad. Sci. 71: 3082-3086.

Yao, M.-C., S.-G. Zhu and C.-H. Yao. 1985. Gene amplification in Tetrahymena: Formation of the extrachromosomal palindromic rDNA. Mol. Cell. Biol. 5: 1260-1267.

Yao, M.C., K. Zheng, and C.-H. Yao. 1987. A conserved nucleotide sequence at the site of developmentally regulated chromosomal breakage in Tetrahymena. Cell 48: 779-788.

Yao, M.-C., C.-H. Yao, and B. Monks. 1990. The controlling sequence for site-specific chromosome breakage in Tetrahymena. Cell 63: 763-772.

Yasuda, L.F. and M.-C. Yao. 1991. Short inverted repeats at a free end signal large palindromic DNA formation in Tetrahymena. Cell 67: 505-516.

Yu, G.-L. and E.H. Blackburn. 1991. Developmentally programmed healing of chromosomes by telomerase in Tetrahymena thermophila. Cell 67: 823-832. 


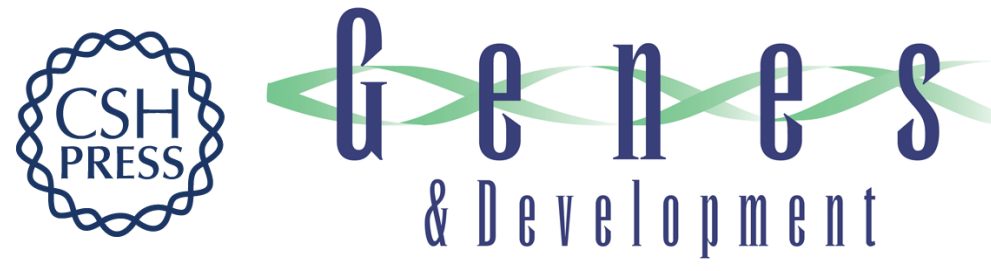

\section{A weak germ-line excision mutation blocks developmentally controlled amplification of the rDNA minichromosome of Tetrahymena thermophila.}

G M Kapler and E H Blackburn

Genes Dev. 1994, 8:

Access the most recent version at doi:10.1101/gad.8.1.84

References This article cites 39 articles, 16 of which can be accessed free at: http://genesdev.cshlp.org/content/8/1/84.full.html\#ref-list-1

License

Email Alerting Service

Receive free email alerts when new articles cite this article - sign up in the box at the top right corner of the article or click here.

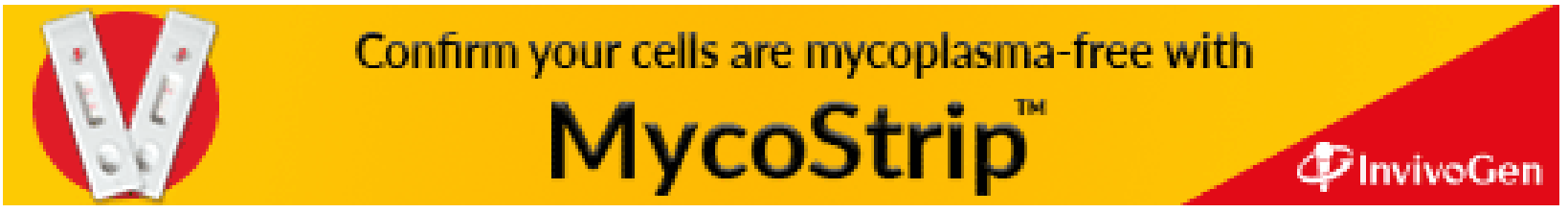

